\title{
La administración temprana de azitromicina podria jugar un rol en la prevención de enfermedad severa y recuurente de las vias respiratorias inferiores en preescolares
}

Early administration of azithromycin could play a role in preventing severe lower respiratory tract illnesses in preschool children

\section{Objetivos}

Evaluar si en niños con enfermedad de la vía respiratoria inferior (EVRI) severa y recurrente, la administración precoz de azitromicina, cuando no hay sibilancias de intensidad grave (SG), evita la progresión a SG.

\section{Diseño}

Ensayo clínico aleatorizado (ECA), doble ciego, controlado con placebo.

\section{Lugar}

Estudio multicéntrico realizado en nueve centros especializados de Neumología Pediátrica de EEUU, desde abril 2011 a diciembre de 2014.

\section{Población}

Se incluyeron 607 preescolares de 12 a 71 meses de edad con EVRI severa y recurrente. Se excluyeron a los que recibían corticoides orales e inhalados, no estaban vacunados, tenían asma grave o no toleraban la azitromicina. Tras la selección hubo un periodo de observación de 4 semanas y aquellos que precisaron medicamentos antiasmáticos también fueron excluidos. El 46,8\% tenían un índice predictivo de asma de alto riesgo.

\section{Intervención}

Se aleatorizó a dos grupos: 307 pacientes recibieron 12 $\mathrm{mg} / \mathrm{kg} /$ día azitromicina durante 5 días y 300 pacientes recibieron placebo, con un seguimiento de 52 a 78 semanas.

\section{Medición del resultado}

El resultado principal fueron niños con al menos una EVRI sin
Bacharier LB y col. JAMA. 2015;314(19):2034-2044 progresión a SG y con requerimiento de corticoides. Esto se consideraba fallo terapéutico, medida por un cuestionario realizado a los padres previamente instruidos sobre la gravedad de la enfermedad. Otros resultados considerados fueron: uso de salbutamol en los episodios, utilización de servicios sanitarios, tiempo trascurrido hasta nuevos episodios, desarrollo de resistencia bacteriana y efectos adversos.

\section{Resultados principales}

Se analizaron 223 niños con azitromicina (excluidos 84 ) y 220 niños con placebo (80 excluidos). La edad media fue 3,5 y 3,35 años respectivamente. El riesgo relativo $(\mathrm{HR})$ de progresión a SG con azitromicina fue 0,64 (IC95\% 0,41 a 0,98) y el absoluto 0,03 (IC $95 \%$ 0,00 a 0,06).

El riesgo acumulativo de SG con un máximo de 4 episodios de EVRI fue de 0,24 con azitromicina y 0,4 con placebo. El número necesario a tratar (NNT) para evitar una SG fue de 33, 14, 10 y 7 a aproximadamente un año para 1,2, 3 y 4 EVRI respectivamente. Los eventos adversos y la inducción de resistencias fueron infrecuentes.

\section{Conclusión}

El empleo de azitromicina precoz durante una enfermedad de tracto respiratorio redujo el riesgo de desarrollar SG, en los niños con EVRI severa y recurrente. Falta información sobre el desarrollo de resistencias con esta estrategia.

Fuente de financiamiento: National Heart, Lung, and Blood Institute (NHLBI). GlaxoSmithKline, Merck, Teva, Boehringer Ingelheim, and Sunovion proveyeron la medicación.

\section{Comentario}

Entre el 14 y $26 \%$ de los niños menores de 6 años presentan episodios de SG, que causan una gran morbilidad y gasto sanitario. ${ }^{1}$ La carga de enfermedad experimentada por los niños de este estudio y sus familias fue significativa, con una media de 4,5 EVRI severas y cerca de 2,5 visitas a guardia por paciente/año. Este es un ECA bien diseñado, pero con una población mal definida (enfermedad de las vías respiratorias), intuyéndose que es el primer episodio de sibilancias. Una debilidad metodológica importante fue el elevado número de pérdidas (27\% grupo azitromicina y $26,5 \%$ placebo). La valoración subjetiva del resultado principal (encuesta a los padres) podría sesgar los resultados (aunque el doble ciego lo protege), y la exclusión de EVRI leve y moderada podrían hacer menos generalizables los resultados. ${ }^{4}$ Por último, el tamaño muestral podría ser insuficiente para detectar diferencias en los resultados secundarios y en los subgrupos. Evaluando la aplicabilidad clínica, según los autores, después de la primera EVRI la toma precoz de azitromicina disminuye un $36 \%$ el riesgo global de recurrencia de EVRI severa, lo que supone NNT para prevenir una SG de 33, (17 en el mejor de los casos). La imprecisión de los resultados, y significancia estadística limítrofe reducen la certeza de la evidencia científica, máxime considerando el alto nivel de pérdidas que podría hacer desaparecer la significancia estadística. Por otro lado, no ha demostrado diferencias en hospitalización, visitas a guardia ni se ha identificado al subgrupo de pacientes con mayor be-neficio, cuestionando su relevancia clínica. Aunque el uso de los macrólidos en las sibilancias es frecuente ${ }^{5}$, su uso rutinario no está avalado por las guías de práctica clínica actuales y podría aumentar las resistencias bacterianas y el gasto sanitario. ${ }^{6}$

\section{Conclusiones del comentador}

La escasa precisión de los resultados y las debilidades metodológicas, sugieren resultados no concluyentes. Es preciso realizar más estudios que definan de forma precisa qué pacientes se beneficiarían más del uso de la azitromicina para la prevención de sibilancias graves, es decir con menores NNT. Muchos autores coinciden en que el beneficio demostrado sea probablemente una combinación de efectos antimicrobianos y antiinflamatorios de la azitromicina. Sin embargo, preocuparía la interpretación de estos resultados, dado que muchos médicos no recordarán los estrechos criterios de inclusión en el estudio y prescribirán tratamiento con azitromicina a otras poblaciones.

Marcela López [ Servicio de Medicina Familiar y Comunitaria del Hospital Italiano de Buenos Aires, marcela.lopez@hospitalitaliano.org.ar ]

López M. La administración temprana de azitromicina podría jugar un rol en la prevención de enfermedad severa y recurrente de las vías respiratorias inferiores en preescolares. Evid Act Pract Ambul. $2016 ; 19(3) 79$. Comentado de: Bacharier LB, y col. Early Administration of Azithromycin and Prevention of Severe Lower Respiratory Tract Illnesses in Preschool Children With a History of Such Illnesses: A Randomized Clinical Trial. JAMA. 2015;314(19):2034-44. PMID: 26575060.

\section{Referencias}

1.Martinez FD, y col. Asthma and wheezing in the first 6 years of life. N Engl J Med. 1995;332:1338.

2. Gómez Acebol J y col. Número necesario de tratamientos: interpretación y estimación en análisis multivariables y con datos censurados. Med Clin (Barc). 2014;142:4516.

3. Martínez González MA y col ¿Qué es una hazard ratio? Nociones de análisis de supervivencia. Med Clin (Barc). 2008;131:6572.

4. Kozyrskyj AL, y col. Antibiotic treatment of wheezing in children with asthma: what is the practice? Pediatrics. 2006;117:e1104e10.

5. Costelloe C, y col. Effect of antibiotic prescribing in primary care on antimicrobial resistance in individual patients: systematic Review and metaanalysis.BMJ. $2010 ; 340:$ : 2096. 